\title{
THE EFFECT OF DEMEROL, ERGOTAMINE, AND DIHYDRO-ERGOTAMINE ON MORTALITY AFTER CORONARY OCCLUSION IN DOGS
}

\author{
BY \\ G. W. MANNING AND G. C. CAUDWELL \\ From the Banting and Best Department of Medical Research, Banting Institute, Toronto, Canada \\ Received February 14, 1947
}

In a previous report (Manning et al., 1939) it was shown that fatal ventricular fibrillation occurred in 75 per cent of untreated conscious dogs following sudden occlusion of the left circumflex branch of the left coronary artery. This mortality can be reduced to 10 per cent by bilateral sympathetic denervation of the heart before ligation (McEachern et al., 1940). It has also been shown that coronary dilator and anti-spasmodic drugs are effective, but to a lesser degree, in reducing this mortality (McEachern et al., 1941; Le Roy et al., 1941, 1942; Gilbert, 1942). These results have been confirmed by Gilbert and his associates whose further work supported the suggestion that a reflex coronary spasm initiated by the occlusion resulted in a generalized myocardial ischæmia which led to the fatal sequence of events (McEachern et al., 1940; Le Roy et al., 1941, 1942; Gilbert, 1942). It was also pointed out that sympathetic denervation may have rendered the myocardium less susceptible to the onset of ventricular tachycardia and fibrillation initiated by the infarction, rather than by interruption of a reflex arc (McEachern et al., 1940). Possibly; both types of mechanism were present.

In view of these findings and the work of others (Leriche et al., 1931; Miller, 1939; Evans, 1940; Katz and Joachim, 1939, 1945; Falk, 1942; Gregg and Shipley, 1944, 1945; Orth, 1946; and Harris, 1946), it was considered advisable to investigate the effect of sympathetic inhibiting agents, using the same experimental conditions and procedure previously described (Manning et al., 1939). For this purpose ergotamine tartrate (Gynergen II, Sandoz) was used and also a new ergot derivative, dihydro-ergotamine (DHE-45, Sandoz).

Stoll and Hoffman (1943) have prepared a crystalline alkaloid derivative by hydrogenation of ergotamine which is less toxic and exerts a sympathetic inhibiting action stronger than ergotamine (Rothlin and Brügger, 1945). Dihydro-ergotamine lowers the blood pressure and slows the heart rate in the narcotized cat and rabbit. It is reported that DHE- 45 acts on effector organs in such a way as to render them indifferent to sympathetic impulses.

Orth (1946) found that $0.4 \mathrm{mg}$./kilo. prevented cyclo-propane-epinephrine induced ventricular fibrillation in the dog. Using rats it was demonstrated that the oxytocic effects did not occur. Gangrene in the rat's tail was rarely produced following large injections of DHE-45 for more than thirty days. The dose recommended by Orth is approximately twice the dose of ergotamine tartrate for the prevention of cardiac effects due to cyclopropane and epinephrine. The protection lasted for about one hour and the epinephrine reversal of blood pressure in anæsthetized dogs did not occur.

Clinical reports have indicated that DHE-45, in doses of $1 \mathrm{mg}$. intramuscularly, is as effective as ergotamine tartrate in the relief of migraine (Horton et al., 1945). It did not produce the disturbing side effects of other ergot preparations and in this dosage it had no demonstrable effect on the uterus, heart rate, blood pressure, peripheral arterial pulsation, or on the temperature and colour of the extremities (Horton et al., 1945; and Hartmann, 1945). 
In view of the results previously obtained (McEachern et al., 1940; Le Roy et al., 1941, 1942; Gilbert, 1942; Falk, 1942; Swanson, 1945; Mokotoff and Katz, 1945; Gerger, 1945; and Lindner and Katz, 1941) with coronary dilator or antispasmodic drugs, it was considered advisable to include in this study a small series of experiments with demerol. The hydrochloride of the ethyl ester of methyl-4-phenylpiperidine-4-carboxylic acid (demerol), discovered in 1939 in Germany (Gruber et al., 1941; and Hori and Gold, 1944), is said to possess antispasmotic or parasympathetic-depressent, analgesic, and sedative effects and has been used clinically for this purpose with some degree of success (Hori and Gold, 1944; and Flatt, 1946).

\section{Methods}

Seventy-two normal dogs were used in these experiments. At operation a loose ligature was placed around the left circumflex branch of the left coronary artery close to its origin as described in a previous report (Manning et al., 1939). The free ends of the loose ligature were brought out of the chest at either end of the skin incision and the chest closed in layers. A sterile dressing protected both the skin incision and the free ends of the ligature. The following day ( 24 hours later) ligation was effected by traction on the loose ends of the ligature.

Three groups of experiments were carried out using demerol, ergotamine tartrate, and dihydro-ergotamine. In addition, 8 dogs were ligated without the use of drugs, as a check on our technique and the mortality rate in conscious dogs, and to increase the original control series. In all cases the drugs were given before the ligation. Electrocardiograms were taken before and after the administration of the drug, before, during, and for 30 minutes after ligation and then intermittently for some time after the occlusion. The animals were observed clinically and with the electrocardiograph for the 24-hour period. An autopsy was performed immediately on all animals that died.

As previously described (Manning et al., 1939) "sudden death" for the purpose of these studies, means death within the first 24 hours. This period for mortality figures on sudden death following coronary occlusion was adopted by us and by others (Le Roy et al., 1941, 1942; and Gilbert, 1942) because most of the animals that fail to survive, succumb shortly after the occlusion (Table I) and up to the present time these studies have been primarily concerned with the immediate mortality following sudden coronary occlusion. Although long-term studies have not been carried out, it has been observed that if the animal survives the 24-hour period it is unlikely that a cardiac death will occur (Manning et al., 1939; and McEachern et al., 1940).

\section{RESULTS}

Control Group. Six of the 8 dogs in which the left circumflex branch was occluded died within the first 24 hours. The sequence of events, including the cardiographic changes, was found to be the same as previously described (Manning et al., 1939; and Le Roy et al., 1941, 1942). In 4 animals ventricular tachycardia and terminal ventricular fibrillation occurred within the first 10 to 12 minutes (Fig. 1 on page 93). Two animals were found dead in 12 to 18 hours following the ligation and the remaining 2 survived. This agrees closely with our earlier results and the findings of others when the left circumflex branch is suddenly occluded in the normal conscious dog. Including the former control series of $16 \mathrm{dogs}$, the mortality for the untreated group was 18 deaths out of 24 dogs within the first 24 hours, or 75 per cent.

Demerol Series. In these experiments 12 dogs were used. Demerol was given intramuscularly in doses of $10 \mathrm{mg}$./kilo. followed by a second injection of $5 \mathrm{or} 10 \mathrm{mg}$./kilo. intravenously 15 to 25 minutes later. Ligation of the left circumflex was carried out in the manner described 10 to 20 minutes following the second injection of demerol.

The sequence of events following occlusion was similar to that seen in the control group except that the animals appeared somewhat more disturbed. The incidence and nature of 
TABLE I

RESULTS

Showing comparison with previous studies and with those of Le Roy et al., 1942

\begin{tabular}{|c|c|c|c|c|c|c|}
\hline \multirow{2}{*}{\multicolumn{3}{|c|}{ Experimental group }} & \multirow{2}{*}{$\begin{array}{c}\text { Number of } \\
\text { dogs }\end{array}$} & \multicolumn{2}{|c|}{ Immediate mortality } & \multirow{2}{*}{$\begin{array}{c}\text { 24-hour } \\
\text { mortality } \\
\text { (percentage) }\end{array}$} \\
\hline & & & & Time (min.) & Percentage & \\
\hline & $\begin{array}{lcl}\text { Control } & . & . \\
\text { Demerol } & \ldots & . \\
\text { Ergotamine } & \text { tartrate } & \ldots \\
\text { DHE-45 } & . . & .\end{array}$ & $\begin{array}{ll}\cdots & \ldots \\
\cdots & \ldots \\
\ldots & \cdots \\
\cdots & \cdots\end{array}$ & $\begin{array}{l}24 \\
12 \\
13 \\
23\end{array}$ & $\begin{array}{c}10-12 \\
2-4 \\
15 \\
2-12\end{array}$ & $\begin{array}{l}50 \\
58 \\
15 \\
13\end{array}$ & $\begin{array}{l}75 \\
58 \\
70 \\
30\end{array}$ \\
\hline 1 & 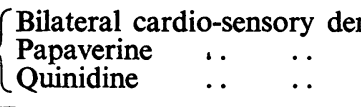 & $\begin{array}{l}\text { lervation } \\
\ldots\end{array}$ & $\begin{array}{l}22 \\
20 \\
20\end{array}$ & $\begin{array}{c}9-15 \\
17 \\
5\end{array}$ & $\begin{array}{r}9 \\
45 \\
45\end{array}$ & $\begin{array}{r}9 \\
50 \\
55\end{array}$ \\
\hline 2 & $\begin{cases}\text { Control } & . \\
\text { Xanthine treated } & \ldots \\
\text { Theobromine treated } & \cdots \\
\text { Theophylline treated } & \ldots \\
\text { Atropine treated } & \ldots \\
\text { Atropine } & . \\
\text { Theophylline and atropine }\end{cases}$ & 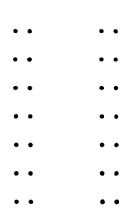 & $\begin{array}{r}13 \\
39 \\
21 \\
18 \\
8 \\
4 \\
6\end{array}$ & $\begin{array}{l}= \\
= \\
= \\
=\end{array}$ & $\begin{array}{l}\bar{z} \\
\bar{z} \\
\bar{z}\end{array}$ & $\left.\begin{array}{l}70 \\
38 \\
23 \\
56 \\
34 \\
50 \\
53\end{array}\right\}$. \\
\hline
\end{tabular}

1. McEachern et al., 1940, 1941; Smith et al., 1940.

2. Le Roy et al., 1942.

pain after the occlusion was variable, being the same or greater in 3 animals, absent in 1 , and somewhat decreased in the remaining 8 . Seven animals died in ventricular fibrillation in 2 to 4 minutes following ligation and the remaining 5 survived the 24-hour period.

The number of animals used does not warrant a statistical comparison of mortality with the control group. However, it would appear that demerol did not afford much protection against cardiac irregularities, tachycardia, and fibrillation, following sudden coronary occlusion. In the cardiogram the effects usually seen following experimental coronary occlusion were observed. There was little or no change in heart rate or rhythm following the injection of demerol. On ligation the typical S-T elevation and $\mathrm{T}$ wave changes occurred (Fig. 2); extrasystoles were common. The outstanding feature, however, was the rapid onset of the ventricular tachycardia, which occurred in eleven experiments and terminated in fatal ventricular fibrillation within 2 to 4 minutes in 7 of the 12 animals. In the control group ventricular tachycardia and fatal ventricular fibrillation usually occurred about 10 to 11 minutes following ligation. Four of the 5 dogs that survived did so in spite of the rapid onset of ventricular tachycardia (Fig. 2 on page 93) which in the control experiments was invariably followed by fatal ventricular fibrillation.

Ergotamine Tartrate Series. In these experiments 13 dogs were used. In the first 2 animals $0.5 \mathrm{mg}$./kilo. ergotamine tartrate was given intravenously. In one of these a severe heart block occurred following the injection of ergotamine and the animal died in fatal heart block 36 minutes after ligation. In view of these effects a dose of $0.25 \mathrm{mg}$. $/ \mathrm{kilo}$. was given to the remaining 11 dogs. Nine of the 13 animals died within the first 24 hours. Two dogs died shortly after the ligation, one in ventricular fibrillation in 9 minutes and the other in 36 minutes with heart block following the occlusion. The remaining 7 died in periods ranging from 9 to 18 hours, following ligation (Fig. 3 on page 94). Shortly after the intravenous injection of ergotamine tartrate the animals showed marked muscular weakness, most apparent in the limbs. Increased respiration and dyspnœa, which in several was of an asthmatic nature, were prominent features. Salivation was also observed. Vomiting occurred in two and bowel 
evacuation in 5 of the 13 animals. The generalized muscular weakness and dyspnoa continued following the occlusion. Throughout the 24-hour observation period these signs continued and were associated with collapsed peripheral veins and pulseless cold extremities. These effects appeared to increase in severity and approached a maximum some 10 hours following the injection and occlusion. In the animals that did not survive, death occurred suddenly about this time, in the same manner as was seen in other experiments in which the animals succumbed shortly after ligation. In 4 dogs a second injection of ergotamine was given 8 to 10 hours following the ligation, but the terminal event was not delayed any longer.

Following the injection of ergotamine tartrate there was a decrease in heart rate in 12 out of 13 dogs. In 6 of the animals varying degrees of S-A and A-V heart block occurred (Fig. 4). The P-R interval was increased by the drug and the QRS interval showed little or no change. In general the $Q R S$ complex and $T$ wave showed inconstant variations in amplitude, the $T$ waves being increased in 2 instances, decreased in 4 , reversed in 1 , and unchanged in the others. In 3 experiments the RS-T segment was depressed following injection of the drug.

Following ligation there was some increase in the heart rate. Extrasystoles were not seen as frequently as in the control group. The ventricular tachycardia frequently seen shortly after ligation occurred in only one animal, this progressed to fatal ventricular fibrillation in 11 minutes following ligation. One other animal died in heart block (in 36 minutes) which was present even before the ligation. Seven of the 9 dogs that did not survive the experiment died in the 12 to 18-hour period following ligation; 1 died in block, 2 in fibrillation, and 4 were found dead in the cage. In general, the rhythm became regular within half an hour following the occlusion, but was followed by a progressive deterioration which reached a maximum 12 hours later. Wide variations in individual dogs were seen, but the most common findings were varying degrees of S-A, A-V, and bundle branch block. An increase in the number of extrasystoles was also noted and auricular fibrillation occurred in 2 dogs; nodal or extrasystolic rhythm occurred in a few and A-V dissociation was also observed. In contrast to other groups there was following ligation a progressive depression of the RS-T segment which had returned or was approaching the base line again in about 30 minutes. Deeply inverted $T$ waves were also common (Fig. 4 on page 94 ).

It was apparent that ergotamine tartrate in doses of $0.25 \mathrm{mg} . / \mathrm{kilo}$. was effective in inhibiting the mechanism of fibrillation and so reduced the "immediate" mortality. A delayed cardiac death, however, occurred 12 to 18 hours later in 70 per cent of the animals.

Dihydro-ergotamine Series. In these experiments 23 animals were used. DHE-45 was given intravenously $(0.4 \mathrm{mg}$./kilo.) 4 to 5 minutes prior to the occlusion. In the majority of cases some degree of salivation occurred within 1 to 2 minutes, but was less than that seen in the ergotamine series. Gastro-intestinal upsets occurred in 2 instances (retching in one animal and vomiting in another about 3 to 4 minutes following the drug). Bowel movement did not occur before ligation, but was frequent shortly after ligation. Respiration was slightly increased by the drug in a few animals as compared with the marked increase and even dyspnœa seen in the ergotamine tartrate series. The drug appeared to have little or no effect on the pain of ligation. Although most of the animals appeared slightly unsteady following the occlusion, the general collapse and weakness and toxic appearance that was such a prominent feature of the ergotamine series was not apparent. Clinically, these animals appeared more like the control dogs that survived the immediate effects of the occlusion. Seven of the 23 dogs died within the 24-hour period following ligation (30 per cent mortality). Three of these died within 12 minutes following occlusion in ventricular fibrillation (13 per cent). The remaining 4 died in 17 to 19 hours after ligation. A statistical comparison of these results; i.e. 30 per cent of 23 dogs as compared to 75 per cent of 24 dogs in the control group, using the chi square method and the Yates correction for small numbers, yielded a chi square of $7 \cdot 4$ and a $\mathrm{P}$ factor of less than $0 \cdot 01$. 
In comparison with the ergotamine tartrate series, it is apparent that DHE-45 was not only similar in its protecting action on the ventricular fibrillating mechanism, but also significantly increased the survival rate.

Following the intravenous injection of DHE-45, electrocardiograms were obtained and compared with those taken immediately before giving the drug (Fig. 5 on page 95). In almost every instance there was a slightly decreased sinus rate. In over 50 per cent of records a slight increase in the P-R interval over the pre-drug record was apparent. In the majority of records there was a small increase in the amplitude of the $T$ waves.

Immediately following ligation there was an elevation of the S-T segment in leads I and II, and this was accompanied by a fast sinus rhythm which persisted during the observation period (Fig. 5). The rhythm was broken by bouts of rapidly forming ventricular extrasystoles, or, in many instances, by only an occasional ectopic beat; in three instances ectopic beats did not occur. Within a half-hour the S-T segment had returned to, or was approaching, the pre-ligation base line.

In the animals dying suddenly following occlusion, there were two instances in which a rapid sinus tachycardia was followed by ventricular tachycardia, ventricular fibrillation, and death within 12 minutes (Fig. 5B). The appearance of ventricular tachycardia did not necessarily mean a fatal termination, for in one instance it was seen to appear in 3 minutes and lasted 25 minutes. Tracings taken 24 hours following the ligation showed for the most part a sinus rhythm. Ventricular extrasystoles were frequent, while $T$ waves were inverted and increased in amplitude.

In two instances a ventricular bigeminal rhythm was noted; in one this appeared shortly after ligation, and the animal died in ventricular fibrillation in 11 minutes. The other was observed in the 24-hour record, and the animal survived the experiment. A 2:1 A-V block occurred in 13 minutes after ligation in one animal, and S-A block was observed in the 24-hour record of another animal, both of which survived.

\section{Discussion}

In previous reports (Manning et al., 1939; and McEachern et al., 1940, 1941) it was suggested that a reflex mechanism that caused constriction of the non-occluded branches, resulting in a generalized ischæmia of the myocardium, may have been responsible for the onset of ventricular fibrillation and the high mortality that followed the occlusion. It was suggested also that the mechanism might be associated with certain areas of myocardium more readily affected by the ischæmic process providing a source for ectopic beats progressing to fatal ventricular fibrillation.

In view of our earlier studies, and the work of others, the prevention of this fatal rhythm seemed to resolve along two pathways. First, by the use of antispasmodic and coronary dilator drugs, which may limit the area of ischæmia to the infarcted portion, and perhaps reduce the amount of non-functioning myocardium. Secondly, by the use of sympathetic inhibiting agents in an attempt to reproduce the results obtained following cardiac sympathectomy (McEachern et al., 1940).

It has been shown that antispasmodic and coronary dilator drugs have some effect in reducing mortality following experimental coronary occlusion (McEachern et al., 1941; Le Roy et al., 1941, 1942; Gilbert 1942; and Gold et al., 1937). Their use in the treatment of coronary occlusion clinically has also been reported (Nathanson, 1936; Gold, 1939; Le Roy et al., 1941; Elek and Katz, 1942; Gilbert, 1942; Falk, 1942; Swanson, 1945; and Gerger, 1945). Consequently, it was anticipated that demerol might decrease the mortality. In these experiments, however, 7 of the 12 dogs died within 4 minutes of the ligation and the remaining 5 survived the observation period. In these 7 cases fatal ventricular fibrillation, recorded by the electrocardiogram, occurred in a shorter period ( 2 to 4 minutes) than that usually seen in 
the control dogs ( 8 to 12 minutes). Over half of the dogs were hyperexcitable and in general it appeared that the more excitable the animal the earlier was the onset of the ectopic rhythm.

Since the pre-fibrillation ventricular rhythm (and fibrillation) occurred so rapidly following the occlusion, it would seem that demerol increased the excitability of the myocardium. Demerol has been used by Gerger (1945) in acute myocardial infarction and by others for the relief of pain, particularly during labour (Hori and Gold, 1944 ; and Flatt, 1946). In the clinical reports on the use of demerol there appears to be no evidence of the exciting or stimulating effect seen in these experiments.

In the experiments carried out with ergotamine tartrate and DHE-45 the "immediate" (i.e. within the first 15 minutes) mortality was considerably reduced, to 15 per cent and 13 per cent respectively, as compared with the control series mortality of 50 per cent in a similar time. It was shown that this was due to the inhibition of fatal ventricular tachycardia and fibrillation. In the ergotamine tartrate group, the mortality had increased to that seen in the control series by 19 hours after the occlusion; this we considered due to the combined effect of drug toxicity and infarction. In the DHE-45 experiments, however, the mortality remained low (30 per cent) approximating the results obtained in the cardio-sensory denervation experiments (10 per cent mortality), although pain did not appear to be influenced. Clinically, the DHE-45 experiments resembled the control experiments, except for the mortality rate which was significantly lower in the DHE series.

In the cardiac sympathetic denervation experiments it was postulated that a possible reflex spasm, with the afferent side of the arc in the sympathetic and the efferent radicles in the vagus, was interrupted. An alternative view was that sympathetic denervation rendered the myocardium less susceptible to the onset of ventricular fibrillation (McEachern et al., 1940). Although the former hypothesis has received support (Le Roy et al., 1941, 1942; and Gilbert, 1942), it is difficult, in view of our recent results with DHE-45, to explain the reduction in mortality entirely on this basis, particularly in view of the more recent work on the nervous and reflex control of coronary blood flow (Katz and Joachim, 1939, 1945; and Gregg and Shipley, 1944 and 1946) which, at the present time, is by no means settled (Gregg, 1946).

DHE-45 acts on effector organs in such a way as to render them indifferent to sympathetic impulses (Rothlin and Brügger, 1945). The drug is, therefore, not effective by interrupting the afferent side of such a reflex arc. If sympathetic efferent fibres carry constrictor impulses to the coronary arteries (Katz and Joachim, 1939), then it is still possible that coronary spasm (reflex or otherwise) may be a factor in the onset of fatal tachycardia and fibrillation following coronary occlusion.

The exciting effects of adrenalin and sympathetic stimulation in producing fatal ectopic heart rhythms experimentally (Wiggers, 1930; Naham and Hoff, 1934; Hoff and Naham, 1935; Melville, 1946; and Philips et al., 1946) and the deleterious effects of sympathetic stimulation and adrenalin in coronary heart disease have been described by various writers (Nathanson, 1936; Eppinger and Levine, 1943; and Raab, 1943, 1944, 1945). From the existing evidence it would appear that these effects are the result of a direct action on the heart rather than secondary to a decrease in coronary flow. A similar myocardial excitability follows sudden coronary occlusion and this can likewise be depressed or inhibited by removal of sympathetic nerves or by inhibition of the sympathetic effector mechanism with DHE-45. It would appear reasonable, therefore, to assume that a direct sympathetic excitor mechanism is an important factor in producing the fatal ectopic rhythm following sudden coronary occlusion. In the cardio-sensory denervation experiments both afferent and efferent fibres have been removed. This may be effective through the abolition of reflex constrictor impulses to the coronary bed, or by the removal of the source of adrenalin, both locally in the heart (Hoffmann et al., 1945) and from the adrenals. In the DHE-45 experiments efferent endings only have been affected; pain was unaffected and it is expected that the amount of circulating 
adrenalin is high but is rendered ineffective by the DHE-45. It has been shown (Hoff and Naham, 1934) that removal of the stellate ganglia and adrenal glands prevents the occurrence of benzol- and electrically-induced ventricular fibrillation, but that if adrenalin is given to the animal fibrillation occurs. Unfortunately, adrenalin was not given in the cardiac denervation experiments. It is possible, however, that complete cardio-sensory denervation by the abolition of pain prevented the release of adrenalin from the adrenals (or possibly locally in the heart) which must occur with the sudden painful and distressing attack. In this connection it is interesting to note that in the sympathectomized series the 2 animals that did not survive the occlusion died in ventricular fibrillation, and both experienced some degree of pain, indicating that cardio-sensory denervation had not been complete.

Furthermore, from the survival times during the 24-hour period (Table I) it appears, both in these studies and in the previous reports, that the "immediate" mortality (i.e. within the first 15 minutes) in the control group and in the animals treated with antispasmodic and coronary dilator drugs is of the same order. During the remainder of the 24-hour period little or no further increase in mortality occurred in the treated group, whereas in the control group the mortality had increased to 75 per cent. Antispasmodic and coronary dilator drugs, therefore, appeared to have no effect on this " initial " mortality (due to ventricular fibrillation). On the other hand, DHE-45 markedly decreased the early initial mortality (13 per cent), but later in the 24-hour period (18 hours) a small further increase of 18 per cent in mortality occurred.

Although experimental findings in the dog cannot be applied directly to coronary artery occlusion in man, the similarity in clinical features is most striking. There are a number of reports of ventricular fibrillation graphically recorded as the terminal event following sudden coronary occlusion in man (Hamilton and Robertson, 1933; Leary, 1935; Nathanson, 1936; Smith, 1939; Miller, 1939; Le Roy and Snider, 1941; Thompson, 1941; and Falk, 1942). Since most patients suffering a sudden coronary occlusion are not seen by the physician for some time, little is known about the frequency of cardiac irregularities immediately following the attack. In patients who survive the immediate occlusion, frequent extrasystoles, ventricular tachycardia, and other cardiac irregularities that lead to ventricular fibrillation are not considered to be common; in all probability the earlier the patient is seen, the more frequently such irregularities will be observed. Furthermore, when sudden death occurs in such cases some hours or days following the occlusion, a rapid and fatal ventricular tachycardia and fibrillation is responsible (see above). Consequently, if therapy that will inhibit the development of a rapid ectopic rhythm can be instituted early, there may be a reasonable hope of reducing the immediate mortality of sudden coronary occlusion. Experimental and clinical studies suggest that such treatment may be further enhanced by the early use of coronary antispasmodic and dilator drugs, presumably through the favourable effects on coronary circulation.

\section{SUMMARY AND CONCLUSIONS}

Sudden occlusion of the left circumflex branch of the left coronary artery in conscious dogs, resulted in fatal ventricular fibrillation in 75 per cent of 24 animals within the first 24 hours (50 per cent within first 15 minutes). Previous studies (McEachern et al., 1940) have shown that this mortality can be reduced to 10 per cent, or less, if bilateral cardiac sympathectomy is carried out prior to the ligation.

Demerol was not effective in reducing the initial mortality and ventricular fibrillation occurred rapidly in all fatal cases (58 per cent of 12 animals). The 24-hour mortality, however, did not increase further during the 24-hour period. Animals that recovered did so in spite of a rapid ventricular tachycardia although this was invariably followed by fatal ventricular fibrillation when it occurred in the control series.

Ergotamine tartrate prevented the occurrence of post-ligation ventricular tachycardia and 
fibrillation in 12 out of 13 dogs. Toxic manifestations were observed in all cases, both clinically and cardiographically, with the result that although survival time was increased the 24-hour mortality rate was unchanged (70 per cent) from that seen in the control group.

Dihydro-ergotamine prevented the occurrence of post-ligation ventricular tachycardia and fibrillation in 20 of 23 experiments. The toxic manifestations seen in the ergotamine tartrate group did not occur. In this group the "immediate" or initial mortality (i.e. within 15 minutes) was 13 per cent and the 24 -hour mortality 30 per cent. It is considered that the drug was effective by inhibiting, through its action on the sympathetic efferents, the ventricular tachycardia and fibrillation that result from sudden coronary occlusion.

A discussion of these results, together with other reports on the effect of sympathetic inhibiting agents and coronary antispasmodic and vasodilator drugs in preventing sudden death following acute coronary occlusion is presented.

We wish to thank Professor O. G. Edholm and Dr. William Evans for their helpful criticism in the preparation of this paper.

\section{REFERENCES}

Elek, S. R., and Katz, L. N. (1942). J. Amer. med. Ass., 120, 434.

Eppinger, E. E., and Levine, S. (1934). Proc. Soc. exper. Biol., N.Y., 31, 485.

Essex, H. E., Herrick, J. F., Mann, F. C., and Baldes, E. J. (1943). Amer. J. Physiol., $138,683$.

Evans, E. I. (1940). Ibid., 129, 353.

Falk, O. P. J. (1942). J. Amer. med. Ass., 119, 1250.

Flatt, W. D. (1946). Canad. med. Ass. J., 55, 43.

Gerger, A. J. (1945). Rhode Island med. J., 28, 793.

Gold, H., Travel, V., and Modell, W. (1937). Amer. Heart J., 14, 284.

- (1939). J. Amer. med. Ass., 112, 1.

Gilbert, N. C. (1942). Bull. N.Y. Acad. Med., 18, 83.

- (1944). M. Clin. North America, 28, 1.

Gregg, D. E., and Shipley, R. E. (1944). Amer. J. Physiol., 141, 382.

(1946). Physiol. Reviews, 26, 28.

Gruber, C. M., Hart, E. R., and Gruber, C. M. Jr. (1941). J. Pharmacol. Exper. Therap., 73, 319.

Hamilton, R. L., and Robertson, H. (1933). Canad. med. Ass. J., 29, 122.

Harris, A. S. (1946). Federation Proc., U.S.A., 5, 41.

Hartman, M. M. (1945). Ann. Allerg., 3, 440.

Hoff, H. E., and Naham, L. H. (1935). Amer. J. Physiol., 110, 675.

Hoffman, F., Hoffman, E. J., Middleton, S., and Talesnik, J. (1945). Ibid., 144, 189.

Hori, C. G., and Gold, S. (1944). Canad. med. Ass. J., 51, 509.

Katz, L. N., and Joachim, K. (1939). Amer. J. Physiol., 126, 395.

-, Wise, W., and Joachim, K. (1945). Ibid., 142, 479.

Leary, T. (1935). Amer. Heart J., 10, 338.

Le Roy, G. V., and Snider, S. S. (1941). J. Amer. med. Ass., 117, 2019.

- Fenn, G. K., and Gilbert, N. C. (1942). Amer. Heart J., 23, 637.

Leriche, R., Herman, L., and Fontaine, R. (1931). Comp. Rend. Soc. Biol., 107, 547.

Lindner, E., and Katz, L. N. (1941). Amer. J. Physiol., 133. 155.

Manning, G. W., McEachern, C. G., and Hall, G. E. (1939). Arch. intern. Med., 64, 661.

McEachern, C. G., Manning, G. W., and Hall, G. E. (1940). Ibid., 65, 661.

, Smith, F. H., and Manning, G. W. (1941). Amer. Heart J., 21, 25.

Melville, K. I. (1946). Federation Proc., U.S.A., 5, 193.

Miller, H. (1939). New. Eng. med. J., 221, 564.

Mokotoff, R., and Katz, L. N. (1945). Amer. Heart J., 30, 215.

Naham, L. H., and Hoff, H. E. (1934). Amer. J. Physiol., 109, 78.

Nathanson, M. H. (1936). Arch. intern. Med., 58, 685.

Orth, O. S. (1946). Federation Proc., U.S.A., 5, 196.

Phillips, F. S., Gilman, A., and Crescitelli, F. (1946). Ibid., 5, 80.

Raab, W. (1943). Arch. Path., 36, 388.

- (1944). Ibid., 38, 110.

- (1944). J. Lab. clin. Med., 29, 715.

- (1945). Ibid., 30, 774.

Rothlin, E., and Brügger, J. (1945). Helv. Physiol. Acta., 3, 519.

Shipley, R. E., and Gregg, D. E. (1945). Amer. J. Physiol., 143, 396.

Smith, F. J. (1939). Amer. Heart J., 17, 735.

Smith, F. H., McEachern, C. G., and Hall, G. E., (1940). Ibid., J., 20, 620.

Stoll, A., and Hoffman, A. (1943). Helv. Chim. Acta., 26, 2071.

Swanson, L. W. (1945). J. Lab. clin. Med., 30, 376.

Thompson, I. (1941). J. Amer. med. Ass., 116, 2583.

Wiggers, C. J. (1930). Amer. Heart J., 5, 351 . 


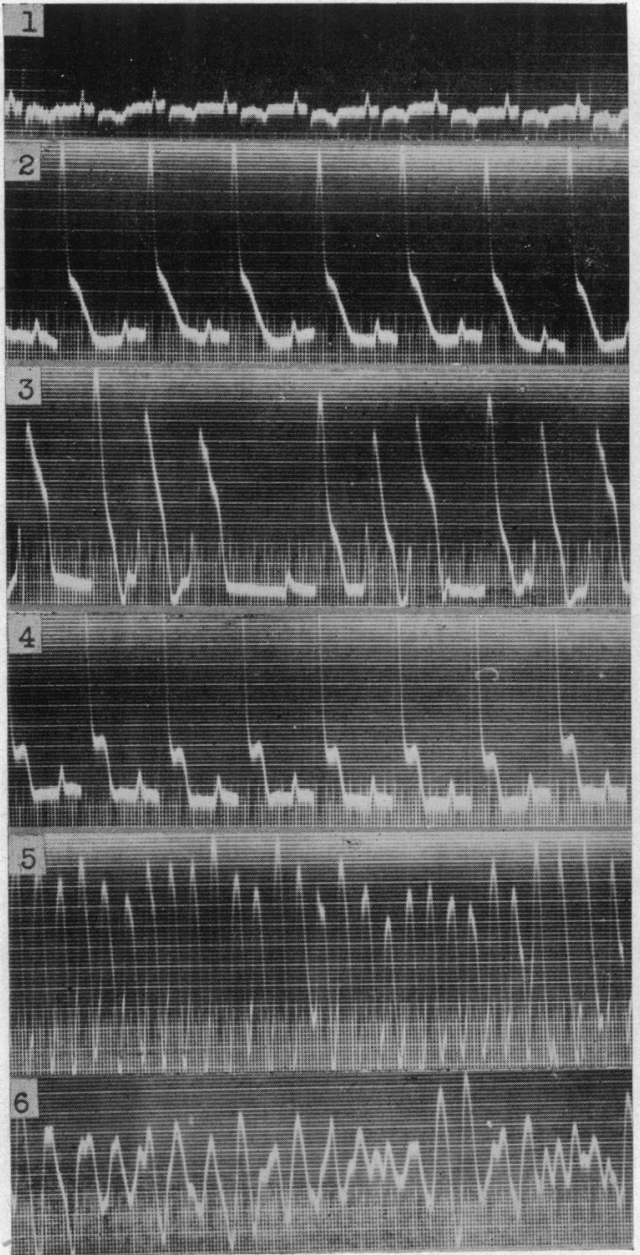

FIG. 1.-Electrocardiograms, lead II, showing typical changes following sudden ligation of the circumflex branch of left coronary artery of the conscious dog (control series). Fatal ventricular fibrillation. (D.3/46.)

(1) Before ligation. (2) Three minutes after ligation. (3) Five minutes after. (4) Eleven minutes after. (5) Twelve minutes after. (6) Thirteen minutes after ligation.

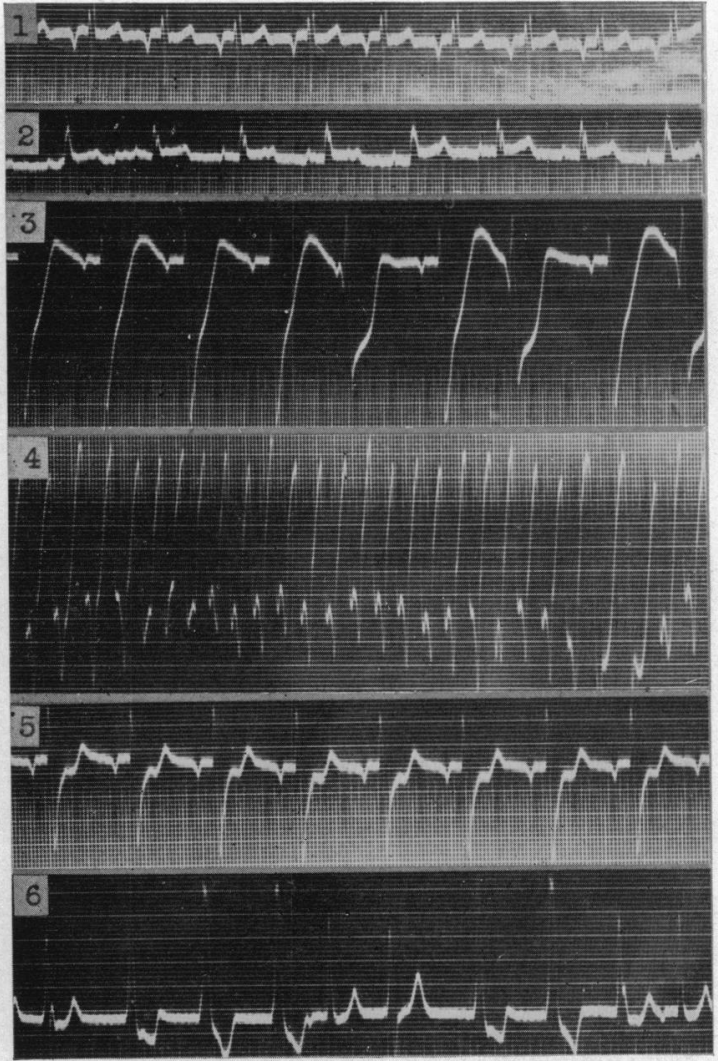

FIG. 2.-Electrocardiograms, lead II, showing typical changes following sudden ligation of the circumflex branch of the left coronary artery of dogs given demerol prior to the occlusion: survival type series of records. Note rapid ventricular tachycardia not followed by ventricular fibrillation, a feature occurring in this group only. (D.19/46.)

(1) Before ligation. (2) Immediately after ligation. (3) Two minutes after. (4) Five minutes after. (5) Twenty minutes after. (6) Twenty-four hours after ligation. 
100

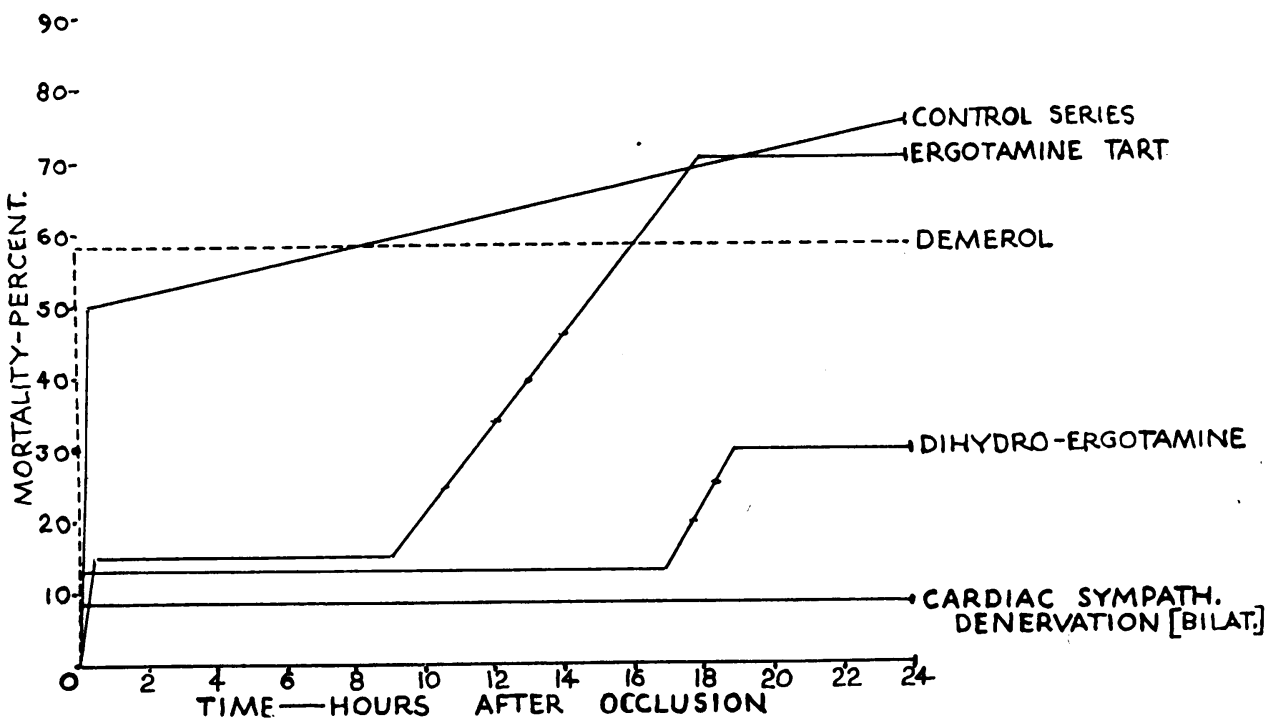

FIG. 3.-Survival times and mortality rates during the 24-hour period following sudden ligation of the circumflex branch of the left coronary artery.

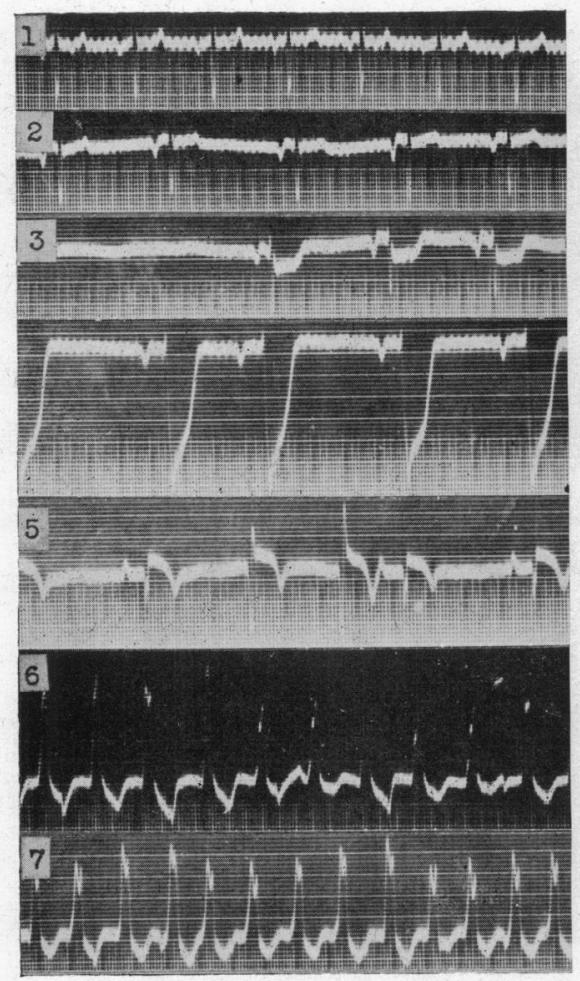

A

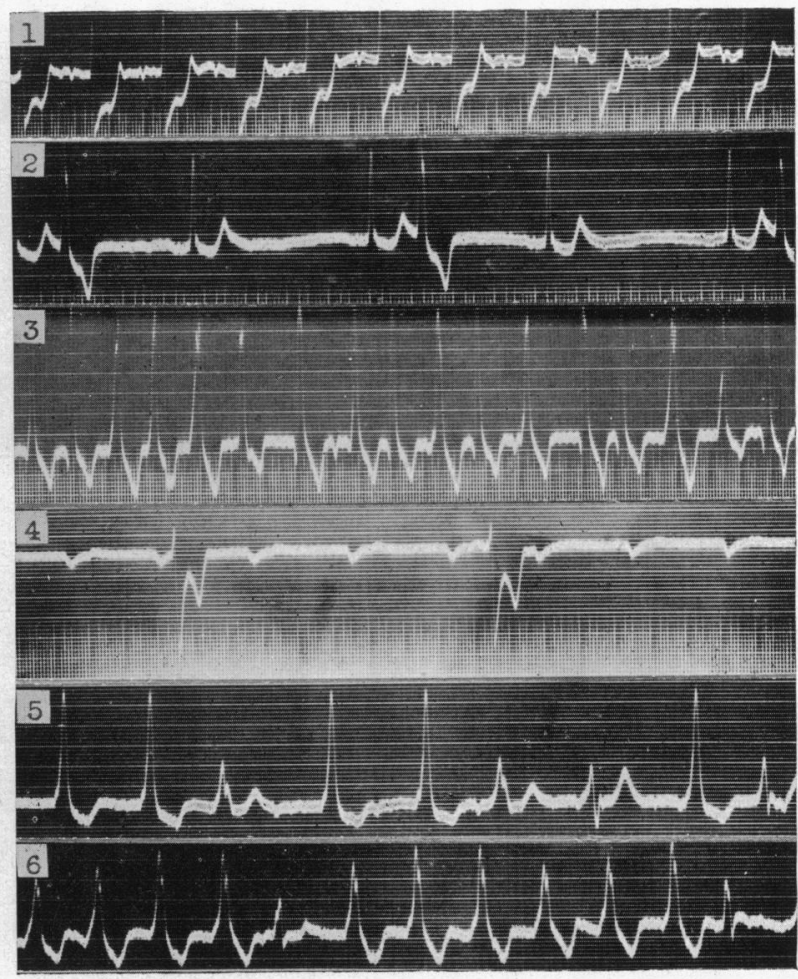

B

FIG. 4.-Electrocardiograms, lead II, following sudden ligation of the circumflex branch of the left coronary artery of dogs given ergotamine tartrate prior to the occlusion:

(A) Survival type series of records. (D.32/46.)

(1) Before ergotamine. (2) After ergotamine and before ligation. (3) One and a half minutes after ligation. (4) Twelve minutes after. (5) Eight hours after. (6) Seventeen hours after. (7) Twenty-four hours after ligation.

(B) Electrocardiograms from several different dogs showing the various abnormalities that occurred in the ergotamine treated group.

(1) D.28, twenty-five minutes after ligation. (2) D.38, eight-and-a-half hours after ligation. (3) D.33, twelve hours after ligation. (4) D.26, thirty minutes after ligation. (5) D.39, fifteen hours after ligation. (6) D.27, five-and-a-half hours after ligation. 


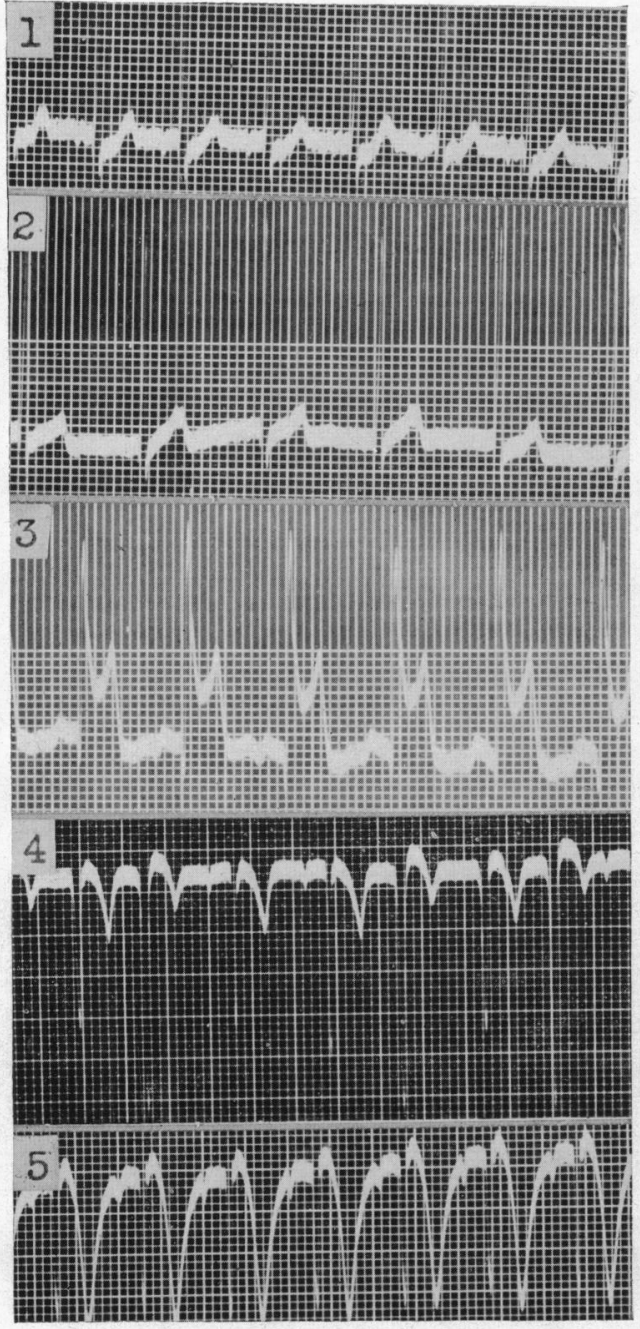

A

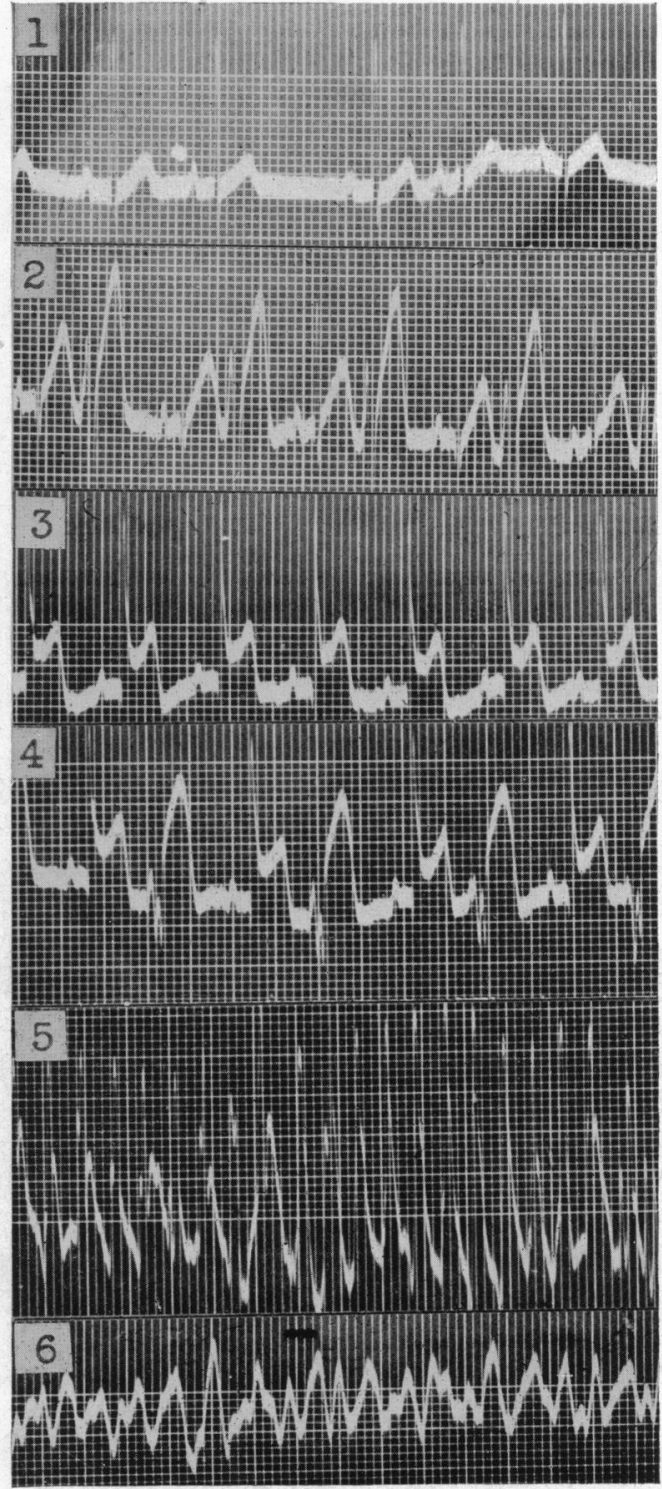

B

FIG. 5.-Electrocardiograms, lead II, following sudden ligation of the circumflex branch of the left coronary artery of dogs given dihydro-ergotamine prior to the occlusion.

(A) Survival type series of records. (D.63/46.)

(1) Before DHE-45. (2) After drug and before ligation. (3) Two-and-a-half minutes after ligation. (4) Twenty-four hours after ligation. (5) Three days after ligation.

(B) Fatal type series of records. (D.47/46.)

(1) Before ligation. (2) Thirty seconds after ligation. (3) One-and-a-half minutes after. (4) Three-and-a-half minutes after. (5) Five minutes after. (6) Six minutes after ligation. 